\title{
Field trips as an intervention to enhance pharmacy students' positive perception of a management module in their final year: A pilot study
}

\author{
M J Eksteen, MPharm; G M Reitsma, PhD \\ Africa Unit for Transdisciplinary Health Research (AUTHeR), Faculty of Health Sciences, North-West University, Potchefstroom, South Africa
}

Corresponding author: M J Eksteen (mariet.eksteen@nwu.ac.za)

Background. Management training is an important aspect of pharmacy training, as many pharmacists are appointed in management positions early in their careers. However, students struggle to see the importance and relevance of a management module in the final year of the BPharm curriculum and show low levels of motivation and engagement with regard to the module. A possible strategy to change students' perceptions of the importance of a management module is the inclusion of field trips in the curriculum.

Objective. To determine whether students' experience of field trips influenced their perceptions regarding a management module as part of their training as future pharmacists.

Methods. A mixed-method sequential exploratory research design was used. Data were gathered through written narratives and focus group interviews, followed by surveys before and after the field trips.

Results. The students who participated in the field trips (experimental group) had higher mean scores in the post-test than those who did not participate (control group). The experimental group was more positive about the module than the control group. The field trips improved the perception of students regarding the importance of the management module for future job preparation.

Conclusion. Field trips add value to pharmacy training and should form part of the BPharm curriculum in South Africa.

Afr J Health Professions Educ 2015;7(2):212-215. DOI:10.7196/AJHPE.436

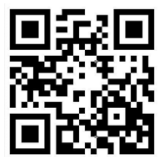

The training of pharmacy students in South Africa (SA) takes place through an intensive 4-year programme. There are 5 major subject groups in the Baccalaureus Pharmaciae (BPharm) curriculum: Pharmacology, Pharmaceutics, Pharmaceutical Chemistry, Clinical Pharmacy and Pharmacy Practice. ${ }^{[1]}$ Pharmacy Practice comprises 7 modules related to the practice of a pharmacist, which includes the patient, medicine distribution, health management and good pharmacy practice, communication, financial management, managed healthcare and general management and human resource management. The last-mentioned module was the context for this study. Students' lack of engagement in introductory management modules, especially non-major modules, is a common phenomenon. ${ }^{[2]}$ This was also the case for an introductory management module for pharmacy students. Students tend to be negative about the module if they do not perceive the work as valuable or important for their development as future pharmacists.

Although the Exit Level Outcomes are prescribed by the South African Qualifications Authority (SAQA), ${ }^{[3]}$ most students have difficulty integrating the theory of management with pharmacy practice. It seems as if they do not see the bigger picture and have difficulty understanding where/ how management fits into their everyday life and professional careers. Students don't realise that pharmacists will very likely be appointed as pharmacy managers about 2 years after graduation owing to the shortage of pharmacists in SA. ${ }^{[4]}$

A possible strategy to influence students' understanding and perception of the importance of a management module is the inclusion of field trips in the curriculum. When planned efficiently, field trips add additional value to and enrich the classroom. ${ }^{[5]}$ Such trips can contribute to and complement the textbook used during formal class lectures ${ }^{[6]}$ and even present better learning outcomes than school-based learning. ${ }^{[7]}$
Such trips assist students in the development of ideas and a deeper understanding around the field/profession and prevent the straightforward memorisation of facts. ${ }^{[6,7]}$ Field trips enhance students' awareness on a cognitive and an affective level, ${ }^{[8]}$ which often cannot be achieved in the classroom. ${ }^{[9]}$ Cognitive learning is achieved when students can make connections among and interpret different aspects of a subject to apply what they have learned in other fields of practice or the profession. ${ }^{[7]}$ Field trips also result in increased memory. ${ }^{[8]}$

From the literature reviewed, field trips are commonly included in subjects such as geography and museum studies, ${ }^{[5-9]}$ biology and ecology ${ }^{[10]}$ and law. ${ }^{[11]}$ In this study, we used field trips as a strategy to influence students' perceptions regarding a management module as part of their training as future pharmacists. The aim of this article is to report, for the first time, on the findings of a research study on the implementation of field trips in a management module in the BPharm curriculum and to conclude whether this intervention changed pharmacy students' perception of the module.

\section{Method}

A mixed-method sequential exploratory research design was followed, where qualitative data were first gathered to explore students' perceptions of the management module. Quantitative data were then gathered to measure the effect of the field trips on the students' perceptions. ${ }^{[12-14]}$ The qual/quant approach started with written narratives, followed by in-depth focus group interviews and a survey (pre-post questionnaire). The purpose of the study, voluntary participation and anonymous handling of data were explained to students before informed written consent was received. An independent researcher in higher education teaching and learning facilitated the datagathering process to ensure anonymity. The North-West University ethics committee granted permission for the study to be done. 


\section{Written narratives}

The first phase of the research included all students who attended the specific management module $(n=156)$ and wrote 1-page qualitative narratives reflecting on the importance and relevance of this module and their expectations of it. The content was analysed to determine trends and patterns ${ }^{[15]}$ from which specific themes were identified for further investigation through focus group interviews. Credibility of this qualitative method was ensured by requesting all students in the class to write the narratives, thus increasing the scope of feedback, providing a safe place and time for students to write anonymous reflections, and explaining the purpose of the process clearly. ${ }^{[16]}$

\section{Focus group interviews}

The second qualitative phase consisted of focus group interviews with the 32 'branch managers' in the class. (All the students who were enrolled for this module formed different groups, referred to as branches, and each group had to appoint a branch manager.) The purpose of the focus group interviews was to explore the themes raised in the written narratives. The independent researcher transcribed the interviews to ensure anonymity, thus conforming to ethical conduct. The transcribed interviews were then analysed ${ }^{[17]}$ through a process of identifying, analysing and reporting patterns in the data. ${ }^{[18]}$ Trustworthiness of the qualitative data was ensured by the engagement of the researchers in the field of research for an extended time (at least one semester) and by applying triangulation ${ }^{[12]}$ by using different methods and different data sources to investigate the same phenomena. The data from the narratives were analysed and the themes were used to inform the focus group questions. The written narratives and transcribed focus group interviews were presented as evidence that the findings were from the data and not the ideas or preferences of the researchers, thus ensuring confirmability (neutrality or objectivity). ${ }^{[19]}$

\section{Pretest survey}

The third phase of research started with a pretest questionnaire. The purpose of the questionnaire was to determine the students' perceptions of the relevance of this module to their current training and their employment after graduation. The questionnaire was compiled based on data gathered from the focus group discussions. Content validity was ensured by formulating the questions from the focus group data. Face validity was ensured by presenting the draft questionnaire to an independent educational researcher and a statistician to evaluate and refine the questionnaire. Nine statements regarding the relevance of the module to practice were formulated. Students had to indicate, on a scale of 1 - 5, their level of agreement with these statements: 1 - do not agree at all, and 5 - agree totally. The quantitative data were analysed using descriptive statistics, e.g. mean and standard deviation (Table 1) and independent samples $t$-test and Cohen's $d$-value.

\section{Population and sample for the survey}

One of the major obstacles in planning a field trip is funding. ${ }^{[21]}$ Because this was a pilot study, the sample was limited to a manageable group within the scope of available time and money. The sample was large enough to provide useful information regarding tendencies in the group that can be investigated in future larger-scale studies. A simple random sample $(20.6 \%$, $n=34)$ of the total number of students who enrolled for the module $(N=165)$ was selected and invited to attend the three field trips. Participation was voluntary and 9 students withdrew. The final experimental group comprised
25 students. The selected students were briefed on what would be required of them during the field trips, the required commitment of attending all three field trips, logistical aspects such as transport and food, ${ }^{[22]}$ and the guarantee that their participation in or withdrawal from this project will in no way influence their marks for the module. Those who did not participate in the field trips formed the control group $(n=140)$.

\section{Field trips}

The main purpose of the field trips was to expose the experimental group to a diversity of real-life scenarios, where the same management principles discussed in theory were applied in the different sectors of the pharmacy profession. The first field trip focused on pharmacists' experience as managers. Students interacted with guest speakers from academia, the corporate pharmacy community and the government sector. The second field trip was a visit to a large corporate pharmacy with different divisions, e.g. an independent community pharmacy, a wholesaler, courier pharmacy and training academy for pharmacy assistants. The third field trip was an excursion to a mining hospital pharmacy chain group.

\section{Post-test survey}

After the intervention, the experimental and control groups completed a post-test questionnaire similar to the pretest one.

\section{Results}

The themes identified from the written narratives included the following: place and value of the management module in the curriculum; students' opinions on the content of the module; possible reasons why students experience this module as a waste of time, their perception being that it is time costly with regard to more important modules; and importance of practical experiences for the students. During the focus group interviews, these themes were further explored and clarified.

Initially, students did not see or understand the importance of the module for their future professional careers. This was evident from comments made during the focus group interviews, such as, 'I don't think we see the value of this module, we have to take it, so we just have to deal with it', and 'They don't see this as important because of their mind set.' Students were negative about this module, because '... anything other than pharmacology is a waste of time. This concurs with Taylor et al's ${ }^{[2]}$ research findings on non-major management modules.

The results of the pre- and post-tests are presented in Table 1. Questions 1 - 3 measured students' perception of the relevance of the management module to practice. The results indicated that the students were positive about the relevance in both the pre- and post-tests. However, there was a slight decrease in the control group's perception in the post-test. Questions 4 and 5 determined whether students were able to link their own practical experience to the module content and whether they needed more practical exposure. Both the experimental and control groups' agreement decreased slightly in the post-test compared with the pretest. The experimental group, however, felt more strongly in the post-test $(d=0.26)$ that they did not see the need for more exposure to practise compared with the control group, where no practical significant difference was measured between the pre- and posttests for this statement. Questions 6 - 9 measured the students' perceptions of how this module prepares them for their future as pharmacists. There was a definite improvement in the experimental group's perceptions of the value of the module for their future employment, with medium practical 
Table 1. Responses of the experimental and control groups regarding relevance of the module to practice before and after the field trips (pre- and post-test)

\begin{tabular}{|c|c|c|c|c|}
\hline Survey questions & Group & $\begin{array}{l}\text { Pretest, } \\
\text { mean }(S D)\end{array}$ & $\begin{array}{l}\text { Post-test, } \\
\text { mean }(\mathrm{SD})\end{array}$ & $\begin{array}{l}\text { Effect size } t \text {-test between } \\
\text { groups E and C for post- } \\
\text { test }(d \text {-value })^{\dagger}\end{array}$ \\
\hline \multirow{2}{*}{$\begin{array}{l}\text { Q1: This module would have been of more use to me if I had completed it before I did my } \\
\text { practical hours in a pharmacy }\end{array}$} & $\mathrm{E}$ & $2.80(1.0)$ & $3.00(1.2)$ & \multirow[t]{2}{*}{0.05} \\
\hline & $\mathrm{C}$ & $2.9(1.1)$ & $3.06(1.2)$ & \\
\hline \multirow[t]{2}{*}{ Q2: According to me, the theoretical content of this module is not related to practice } & E & $1.52(0.5)$ & $1.60(1.0)$ & \multirow[t]{2}{*}{0.14} \\
\hline & $\mathrm{C}$ & $1.70(0.7)$ & $1.74(0.8)$ & \\
\hline \multirow[t]{2}{*}{ Q3: The module content is completely unrelated to practice } & $\mathrm{E}$ & $1.48(0.6)$ & $1.48(0.7)$ & \multirow[t]{2}{*}{0.28} \\
\hline & $\mathrm{C}$ & $1.80(0.9)$ & $1.74(0.9)$ & \\
\hline \multirow{2}{*}{$\begin{array}{l}\text { Q4: I easily understand the work in the module because I can think of practical examples } \\
\text { for most of the concepts }\end{array}$} & E & $4.16(0.6)$ & $4.00(0.9)$ & \multirow[t]{2}{*}{0.15} \\
\hline & $\mathrm{C}$ & $4.01(0.8)$ & $3.86(0.9)$ & \\
\hline \multirow[t]{2}{*}{ Q5: It isn't really necessary to add more practical exposure to this module } & $\mathrm{E}$ & $2.16(0.9)$ & $2.48(1.2)$ & \multirow[t]{2}{*}{0.06} \\
\hline & $\mathrm{C}$ & $2.53(1.1)$ & $2.56(1.1)$ & \\
\hline \multirow[t]{2}{*}{ Q6: I see this module as useful to me as prospective pharmacist } & E & $4.60(0.5)$ & $4.68(0.6)$ & \multirow[t]{2}{*}{0.59} \\
\hline & $\mathrm{C}$ & $4.42(0.6)$ & $4.22(0.8)$ & \\
\hline \multirow{2}{*}{$\begin{array}{l}\text { Q7: The knowledge and skills that I am learning in this module are what I will need one } \\
\text { day in my job }\end{array}$} & $\mathrm{E}$ & $4.44(0.7)$ & $4.56(0.8)$ & \multirow[t]{2}{*}{0.62} \\
\hline & $\mathrm{C}$ & $4.21(0.7)$ & $4.04(0.8)$ & \\
\hline \multirow[t]{2}{*}{ Q8: To some degree I can understand how this module will help me some day in practice } & $\mathrm{E}$ & $4.4(0.5)$ & $4.36(0.6)$ & \multirow[t]{2}{*}{0.33} \\
\hline & $\mathrm{C}$ & $4.17(0.7)$ & $4.10(0.8)$ & \\
\hline \multirow{2}{*}{$\begin{array}{l}\text { Q9: I can't really see how the knowledge and skills in this module are necessary for my job } \\
\text { one day }\end{array}$} & $\mathrm{E}$ & $1.88(1.1)$ & $1.52(0.6)$ & \multirow[t]{2}{*}{0.42} \\
\hline & $\mathrm{C}$ & $1.73(0.8)$ & $1.95(1.0)$ & \\
\hline
\end{tabular}

significance measured in Question $6(d=0.59)$ and Question $7(d=0.62)$. Questions 2, 3, 5 and 9 were stated in a negative sense; therefore, the low means indicate that the students did not agree with the negative statement.

\section{Discussion}

The impact of an intervention in the form of field trips on student perceptions was researched through an exploratory mixed-method approach. By increasing student engagement through field trips, the researchers aimed to influence students' perceptions regarding the value and importance of the module. Evidence from the quantitative phase indicated that these field trips did have a positive impact on students' perceptions. Contrary to the findings from the focus groups, the students as a class were not as negative about the management module as first perceived, as is evident from the higher than average pretest means for the experimental and control groups (Table 1). The effect sizes indicated no significant difference between the experimental and control groups in the pretest.

In the post-test, the mean scores for the experimental group increased for most of the items, indicating a more positive perception of the module. However, the control group's responses were more negative in the post-test, indicating that they still did not understand the value of the module in preparing them for their future positions. This may be because few students had to apply management knowledge and skills in their previous practical work. They explained this as follows: 'The younger you are, the less you do in the pharmacy. First you only wash shelves and it is only in your third year that you start with dispensing' and 'They [the pharmacy staff] don't really give you more to do'. Students may have difficulty linking the concepts addressed in the module to practical examples owing to limited exposure to practice.

The means of all the questions in the pretest for the experimental and control groups indicate that there was already a positive expectancy towards the importance of this module in the BPharm curriculum before the intervention. This was in contrast to what the lecturer perceived at the beginning of the semester with regard to student comments.

Overall, the means for the experimental group were higher than those for the control group, although the difference was only practically significant for Questions 6 and 7. The field trips as intervention did contribute to the experimental group having a better understanding of the importance of this module towards their future roles as pharmacists. The experimental group better understood that the knowledge and skills taught in this module are important for their future employment. Understanding the significance of what they learn, may influence their perceptions positively. Marzano ${ }^{[23]}$ explained the importance of assisting students to develop positive attitudes and perceptions about learning, without which they have little chance of learning proficiently, if at all. If students have certain attitudes and perceptions, they have a mental climate conducive to learning. If those attitudes and perceptions do not exist, learners have a mental climate not conducive to learning.

\section{Conclusion}

Students' negative perception of introductory non-major management modules is a common phenomenon at universities. In this study, field trips were implemented as an intervention to determine whether students' 
experience of field trips influence their perceptions regarding a management module as part of their training as future pharmacists. This was motivated by the comments made by students and confirmed during analysis of written narratives and focus group interviews. The survey results showed that the field trips did not have a practically significant effect on students' overall positive perception of the relevance of this module to practice. This may have been because of high mean scores measured in the pretest, indicating that students were already positive about the module and its relevance to practice. It is, nonetheless, evident that students who did not participate in the field trips did not show the same positive perception of the module as those who did partake in the trips, as there was a clear tendency towards higher mean scores in the post-test results of the experimental group. The field trips influenced students' perceptions of the importance of the module for their future positions. Therefore, it can be concluded that field trips in the management module in the BPharm curriculum changed students' perception positively towards this module.

Although the quantitative study did not statistically prove the positive impact of field trips on all the concepts measured, the experimental group gained more from this experience than those students who did not participate in the field trips. Field trips may have a positive effect on student perception and it is recommended that such trips should be included in the teaching-learning repertoire of modules in the pharmacy curriculum to expose students to relevant practices.

Furthermore, this study indicated that student comments and conversations may provide important information regarding teaching and learning that should be taken into consideration in planning and presenting modules. Student voices on teaching-learning aspects may provide useful and critical information for lecturers to improve their teaching. Lecturers should include more opportunities for conversations through focus group discussions or reflective narrative writing to gain insight into student experiences.

The researchers acknowledge that including only a small sample of the students from the same class for the field trips may be a limitation to the study. As there was lack of funding, not all students were invited to attend the field trips. Also, possible 'contamination' could have taken place as the experimental and control groups were students from the same class and informal discussions could have taken place between students discussing the field trips and their experience thereof.

\section{References}

1. North-West University. Yearbook of the Faculty of Health Sciences, Undergraduate. Potchefstroom: North-West University, 2014.

2. Taylor SA, Hunter GL, Melton H, Goodwin SA. Student engagement and marketing classes. Journal of Marketing Education 2011;33(1):73-92. [http://dx.doi.org/10.1177/0273475310392542]

3. South African Qualifications Authority. Registered Qualification: Bachelor of Pharmacy. Pretoria: SAQA, 2011 3. South African Qualifications Authority. Registered Qualification: Bachelor of Pharmacy.
http://regqs.saqa.org.za/viewQualifications.php?id=72784 (accessed 11 February 2014).

http://regqs.saqa.org.za/viewQualifications.php?id=72784 (accessed 11 February 2014).
4. South African Pharmacy Council. Pharmacy Human Resources in South Africa. Pretoria: South African South African Pharmacy
Pharmacy Council, 2011 .

5. Sturm H, Bogner FX. Learning at workstations in two different environments: A museum and a classroom. Studies in Educational Evaluation 2010;36(1):14-19. [http://dx.doi.org/10.1016/j.stueduc.2010.09.002

6. Demirkaya H, Atayeter Y. A study on the experiences of university lecturers and students in the geography field trip. Procedia Social and Behavioural Sciences 2011;19:453-461. [http://dx.doi.org/10.1016.j.sbsp ro.2011.05.154]

7. Gill N, Adams M, Eriksen C. Engaging with the (un)familiar: Field teaching in a multi-campus teaching environment. J Geogr Higher Educ 2012;26(2):259-275. [http://dx.doi.org/10.1080/03098265.2011.619523]

8. Falk JH, Dierking LD. School field trips: Assessing their long-term impact. Curator 1997;40(3):211-218.

9. Sanders M. Planning a fieldtrip to the Cradle of Humankind: A model of factors affecting the success of educational museum visits. 18th Annual Meeting of the South African Assosiation for Research in Mathematics Science and Technology Education, 18 - 21 January 2010, Durban, South Africa. http://www.saarmste.org/ Science and Technology Education, 18
conferences (accessed 10 February 2014)

10. Lei SA. Field trips in college biology and ecology courses: Revisiting benefits and drawbacks. J Instruct Psychol 2010;37(1):42-48

1. Higgins N, Dewhurst E, Watkins L. Field trips as teaching tools in the law curriculum. Research in Education 2012;88:102-106.

12. Creswell JW, Plano Clark VL. Designing and Conducting Mixed Methods Research. 2nd ed. California: Sage, 2011

13. Macmillan J, Schumacher S. Research in Education. Evidence-Based Inquiry. New York: Pearson, 2014

14. Drew CJ, Hardman ML, Hosp JL. Designing and Conducting Research in Education. Los Angeles: Sage, 2008.

15. Mayring P. Qualitative Content Analysis. Forum: Qualitative Social Research, 2000. http://www.qualitativeresearch.net/index.php/fqg/article/view/1089/2385 (accessed 15 April 2014).

16. Graneheim UH, Lundman B. Qualitative content analysis in nursing research: Concepts, procedures and measures to achieve trustworthiness. Nurse Educ Today 2004;24:105-112. [http://dx.doi.org/10.1016/..nedt.2003.10.001]

17. Vaismoradi M, Turunen H, Bondas T. Content analysis and thematic analysis: Implications for conducting a qualitative descriptive study. Nurs Health Sci 2013;15:398-405. [http://dx.doi.org/10.1111/nhs.12048]

18. Braun V, Clarke V. Using thematic analysis in psychology. Qualitative Research in Psychology 2006;3(2):77-101 [http://dx.doi.org/10.1191/1478088706qp063oa]

19. Tobin GA, Begley MC. Methodological rigour within a qualitative framework. J Adv Nurs 2004;48(4):388-396.

20. Cohen J. A power primer. Psychol Bull 1992;112(1):155-159.

1. Anderson D, Kisiel J, Storksdieck M. Understanding teachers' perspectives on field trips: Discovering common ground in three countries. Curator 2006;49:365-386.

22. Kent M, Gilbertson DD, Hunt CO. Fieldwork in geography teaching: A critical review of the literature an approaches. J Geogr Higher Educ 1997;21(3):313-332.

23. Marzano RJ. A Different Kind of Classroom: Teaching with Dimensions of Learning. Alexandria, VA: Association for Supervision and Curriculum Development, 1992. 